\title{
Política de Formação de Professores no Brasil: alcance das ações por meio da educação a distância.
}

\author{
Rosely Zen Cerny - UFSC - rose@ ced.ufsc.br \\ Sabrina Botelho Kons - UFSC - sabrina.kons@gmail.com \\ Karina Bernardes de Oliveira e Silva - UDESC - bernardeska@ gmail.com \\ Graziela Gomes Stein Teixeira - UFSC - grazisteintex@ hotmail.com
}

\section{Resumo:}

O estudo apresenta um panorama da formação de professores realizada por meio da educação a distância $(\mathrm{EaD})$, procurando evidenciar que esta modalidade de ensino tem sido utilizada de forma prioritária para dar conta da histórica necessidade de formação de professores no Brasil. As universidades públicas são chamadas para, num curto período de tempo, formar um grande número de professores. Neste artigo trazemos um recorte de uma pesquisa que tem como objetivo acompanhar e avaliar a política de formação de professores realizada por meio da $\mathrm{EaD}$, pelo Programa Universidade Aberta do Brasil (UAB). A metodologia utilizada neste artigo é resultado de uma pesquisa de natureza exploratória, descritiva e de abordagem qualitativa e quantitativa. $\mathrm{O}$ processo de mapeamento dos dados sobre a formação de professores realizada na modalidade a distância evidenciou a discrepância das informações entre as instituições públicas de ensino superior (IPES) e UAB. Os dados demonstram que as universidades federais responderam fortemente à política governamental, com uma oferta expressiva de cursos de licenciatura nas diferentes regiões do país, mas que, no entanto, a oferta dos cursos não corresponde ainda às reais necessidades de formação de professores apontadas pelas estatísticas oficiais.

Palavras-chave: formação de professores - educação a distância - ensino superior

\section{Brazilian Politics for Teachers' Formation: the scope of distance education actions.}

\section{Abstract:}

This study presents an overview of teacher training made by distance education $(\mathrm{EaD})$, trying to emphasize that this method of teaching has been used as a priority way to give support for the historical needs of teacher training in Brazil. Public universities are called to, in a short period of time, qualifying a large number of teachers. In this article, we bring a part of a research that aims go in and evaluate the policy of teacher training offered by $\mathrm{EaD}$, by the Open University Program of Brazil (UAB).The methodology used, in this article, is a result of an exploratory research, descriptive and a qualitative quantitative approach. The process of mapping data about teacher training made in the distance modality emphasized the discrepancy of information between public institutions of higher education (IPES) and UAB. The data shows that the federal universities have answered strongly to the government policy, offering a significant licentiate degree courses in different regions of the country, but the offering of courses does not match the actual training needs of teachers, indicated by official statistics.

Keywords: teachers' formation - distance education - higher education 


\section{A Educação a Distância e as novas relações no Ensino Aprendizagem.}

As inovações tecnológicas provocaram grande impacto em nossa sociedade, especialmente a partir da segunda metade do século XX. As transformações ocorridas no mundo atual são mais profundas e rápidas do que em períodos precedentes, instituindo modos de vida extremamente diferentes dos modelos anteriores (GIDDENS, 1991). O uso das Tecnologias de Informação e Comunicação (TIC) produzem mudanças, também, no panorama educacional e desta forma, o conhecimento legitimado no modo de viver dos indivíduos abrem novas possibilidades para o modo de ensinar. Almeida (2010, p.68) considera que:

O final do século 20 e o início do século 21 são caracterizados pela mudança espaço-temporal, pela mobilidade funcional, pela globalização econômica, pelo impacto das tecnologias digitais de informação e comunicação (TDIC) em todos os ramos da atividade humana, pela provisoriedade do conhecimento e pela evolução da ciência. Tais transformações evidenciam, de um lado, a fragilidade da formação inicial como garantia do emprego e, de outro, a necessidade de aprendizagem permanente e ao longo da vida para a participação ativa na sociedade e a inclusão social.

O perfil dos sujeitos que estão inseridos na "sociedade global da informação" (BARRETO, 2009, p.42), demanda novas e permanentes aprendizagens, abrindo possibilidades para outras formas de comunicação. Nesse sentido, Cerny; Kons e Teixeira (2010, p.2) afirmam que:

O uso das Tecnologias de Informação e Comunicação é responsável pela criação de novas formas de relacionamento, pesquisa, gestão, interação, entre outros, ao produzir mudanças significativas na forma como as pessoas se comunicam e interagem, ao mesmo tempo em que possibilitam novas perspectivas educacionais.

As tecnologias oferecem inúmeras possibilidades para o ensino superior e para a pesquisa, assim como para a promoção e a divulgação do saber (MAYOR, 1997). É o avanço das tecnologias que impulsiona fortemente a educação a distância nos dias atuais, mesmo essa modalidade existindo de longa data (CERNY, 2009).

Neste contexto de mudança, este estudo visa conhecer o alcance da política de formação de professores realizada por meio da $\mathrm{EaD}$, identificando os cursos, regiões e instituições públicas de ensino superior que realizam estas formações. Além disso, procura-se também evidenciar a discrepância entre os dados apresentados pelos órgãos governamentais e pelas IPES. Esta é a primeira etapa de uma pesquisa que pretende fazer o acompanhamento dessas experiências, identificando os avanços e desafios das IPES ao assumirem esta tarefa: formar um grande número de professores num curto período de tempo.

\section{Contexto da EaD: da expansão à criação da UAB}

A rápida expansão da $\mathrm{EaD}$ no Brasil a partir de 2004 está associada à adoção desta modalidade de ensino para ampliação das vagas no ensino superior público, assim como para suprir a urgente demanda de formação de professores. Alonso (2010, p.1320) salienta que "no mote da expansão da $\mathrm{EaD}$, dois temas são recorrentes: a democratização do acesso ao ensino superior e a necessidade da formação dos 
profissionais da educação, como fator para melhoria da qualidade do ensino fundamental e médio".

A EaD intensifica-se de forma acelerada como uma modalidade de educação considerada adequada para atender a novas e crescentes demandas por formação. Nas universidades públicas, esta modalidade tem aparecido como recomendação prioritária no discurso das políticas públicas para a democratização do ensino superior, promovendo a expansão e a interiorização da oferta de cursos de formação de professores.

Nesse contexto, se intensifica a chamada para que as universidades públicas se envolvam profundamente neste processo. Cabe enfatizar que algumas delas já contavam com experiências consolidadas em cursos de graduação via $\mathrm{EaD}$, mas que, para outras, isto se configurou como uma atuação inédita (CERNY, 2009). No entanto, é preciso cautela no que se refere à implementação e desenvolvimento dos cursos $\mathrm{EaD}$, pois conforme Belloni (2002, p. 124):

\begin{abstract}
No Brasil (país historicamente dado a grandes experimentos tecnológicos inovadores na educação, que acabam por se tornar "elefantes brancos", pela incúria do poder público e visão tacanha do setor privado), tem havido experiências de educação a distância nas quais se pode observar algumas características estruturais recorrentes: as políticas públicas do setor têm um caráter tecnocrático, autoritário e centralizador que as destina necessariamente a resultados medíocres, senão ao fracasso, ao passo que a iniciativa privada vai ganhando terreno, construindo competência e obtendo verbas públicas.
\end{abstract}

Segundo Martins (2008), apesar da resistência demonstrada em relação ao ensino a distância, essa modalidade obteve na década de 1990 um grande avanço com a aprovação da Lei e Diretrizes e Bases da Educação Nacional (LDBN, Lei no 9.394, de 20/12/1996), que aprovou a Educação a Distância como uma modalidade para o sistema de ensino brasileiro. A partir da promulgação da $\mathrm{LDBN}$, marco inicial para o processo de reconhecimento da $\mathrm{EaD}$, segue-se uma série de regulamentações que incentivam o uso das tecnologias de informação e comunicação na educação e uma estrutura jurídicolegal foi aprovada para dar sustentação ao sistema de $\mathrm{EaD}$, visando sua implementação como uma via que possibilitará um futuro discurso sobre a democratização no ensino superior.

Cerny (2009, p. 46) salienta que:

É no governo de Luiz Inácio Lula da Silva (2003-2006 e 2007-2010) que uma série de políticas de expansão do ensino superior por meio da educação a distância são propostas visando a democratização e interiorização do ensino público. Uma das suas primeiras ações nesta área é a criação, em 2004, do Fórum das Estatais pela Educação, com o objetivo de "propiciar espaço de diálogo e interlocução entre o MEC, Governo Federal e Estatais brasileiras para análise e debate das questões estratégicas ligadas ao desenvolvimento sustentável do país, com especial destaque para a busca de soluções para os problemas ligados à educação" (BRASIL, 2004c, sem paginação). A criação do Fórum faz parte de um conjunto de políticas do Governo Luiz Inácio para a área educacional, apresentando como meta angariar investimentos para a educação, especialmente para os programas voltados para a expansão da educação superior. Trata-se do ponto de partida para a criação do Sistema Universidade Aberta do Brasil (UAB).

A Universidade Aberta do Brasil foi instituída pelo Ministério da Educação (MEC), a partir do Decreto 5.800/2006, sendo apresentada como um sistema "voltado 
para o desenvolvimento da modalidade de educação a distância, com a finalidade de expandir e interiorizar a oferta de cursos e programas de educação superior no País" (BRASIL, 2006, p.1). Entre seus objetivos principais estão a oferta prioritária de cursos de licenciatura e a expansão e interiorização do ensino público superior.

A implementação dos cursos aconteceu, inicialmente, por meio de consórcios regionais $^{1}$ e o MEC, com objetivo de favorecer a troca de experiências entre as universidades. Na seqüência, as universidades habilitaram-se ao oferecimento dos cursos individualmente, de preferência com uma oferta elevada de vagas.

É este o cenário para as universidades públicas: o desafio de democratizar o ensino superior público por meio da educação a distância. $\mathrm{O}$ movimento ocasionado por essas novas demandas é analisado neste estudo a partir do olhar sobre as instituições públicas de ensino que encampam as atuais políticas de expansão via $\mathrm{EaD}$.

\section{A Pesquisa}

A proposta metodológica se traduz em uma pesquisa de cunho quantiqualitativo, que envolve o mapeamento e acompanhamento de cursos de formação inicial e continuada de professores oferecidos na modalidade a distância por instituições públicas de ensino superior. Esta opção justifica-se por considerar que o método é o corpo de princípios que sustenta toda a pesquisa. Nos últimos tempos, tem-se presenciado uma discussão intensa a respeito das possibilidades de se combinar os dois tipos de método (quantitativo e qualitativo), sendo que um número crescente de investigadores educacionais vem adotando essa postura. A diferença entre estas duas perspectivas metodológicas é apenas de natureza, pois, enquanto a abordagem quantitativa apreende dos fenômenos à parte visível, ecológica, morfológica e concreta, a abordagem qualitativa procura aprofundar-se no mundo dos significados das ações e relações humanas, um lado não perceptível e não captável em equações, médias e estatísticas. Neste sentido, não existe a oposição quantitativo-qualitativo. Ao contrário, essas duas perspectivas são perfeitamente complementares.

A abordagem qualitativa caracteriza-se, neste estudo, pela busca da compreensão do fenômeno em seu contexto, privilegiando essencialmente o entendimento dos dados quantitativos. Nesta perspectiva o pesquisador assume uma atitude aberta em relação ao que observa, para ter uma compreensão global do objetivo a ser estudado. A investigação qualitativa caracteriza-se também pela coleta de dados ricos em pormenores descritivos a pessoas, locais e conversas, e de complexo tratamento estatístico (CERNY, 2009).

Considerando este aporte metodológico e com o objetivo de identificar as universidades públicas que oferecem cursos a distância no Brasil, optou-se primeiramente por buscar esta informação no portal da UAB na Coordenação de Aperfeiçoamento de Pessoal de Nível Superior $\left(\mathrm{CAPES} / \mathrm{UAB}^{2}\right)$. Nele foram identificadas 75 instituições ${ }^{3}$ participando das ações da UAB, das quais 48 se referem a universidades federais e 27 estaduais. De posse destas informações, procurou-se identificar, ainda no mesmo portal, os cursos de formação de professores em nível de licenciatura e especialização em cada instituição elencada na fase anterior.

$\mathrm{Na}$ etapa seguinte, procedeu-se nova pesquisa, agora nos portais de educação a distância das instituições públicas de ensino superior (IPES/EaD), a fim de ratificar os dados coletados no portal CAPES/UAB. A partir de uma análise comparativa, observou-se que as informações disponibilizadas pelas IPES e pela CAPES/UAB eram 


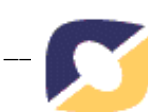

divergentes e que, inclusive, os dados dos cursos de uma mesma instituição eram veiculados de maneiras distintas nos portais das instituições.

Essa discrepância sinalizou o surgimento de possíveis dificuldades em trabalhar com os dados divulgados pelas CAPES/UAB. A título de ilustrar esta diferença, tomase o exemplo da $\mathrm{U}^{4}$, que no site da CAPES/UAB apresenta nove cursos de licenciatura na modalidade $\mathrm{EaD}$, enquanto que no site oficial da IPES/EaD aparecem apenas cinco, como é possível observar na Figura 1.
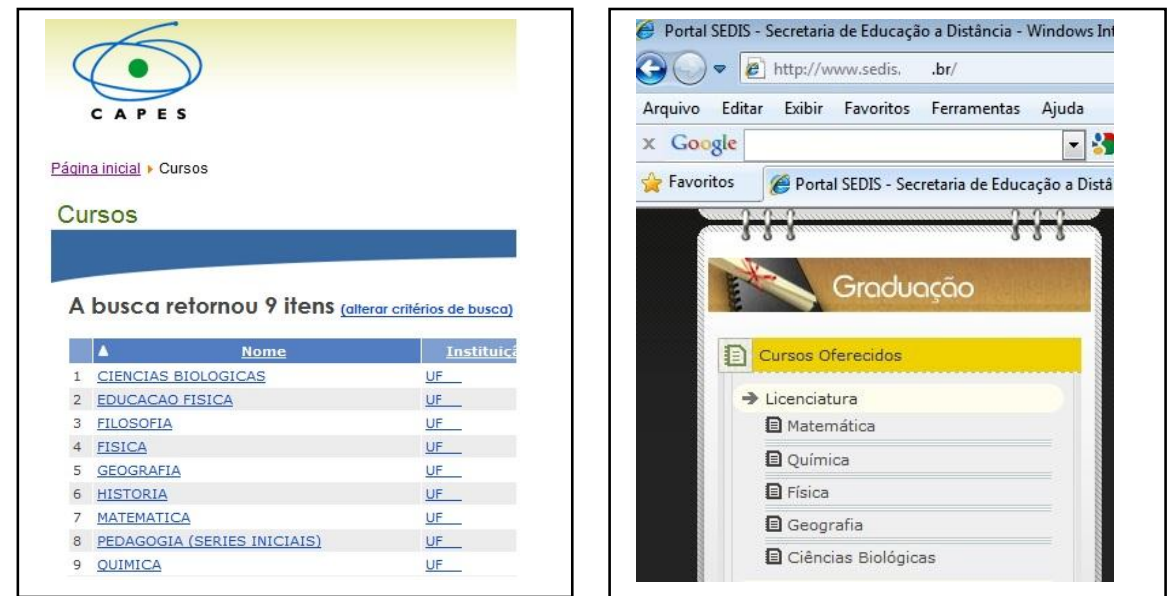

Figura 1: Exemplo da distorção de informações entre CAPES/UAB e site da IPES/EaD (U1)

Diante deste panorama, elaborou-se uma tabela geral na qual foram confrontados os dados disponibilizados em ambas as bases de dados. Para este estudo especificamente, coloca-se aqui apenas um recorte da mencionada tabela.

Tabela 1: Comparação entre os dados da CAPES/UAB (C1, C2, C3 e C7) e sites IPES/EaD (C1, C3, C4, C5, C6, C8 e C9) - Região Norte

\begin{tabular}{||c|c|c|c||}
\hline \multirow{2}{*}{ IE } & N & \multicolumn{2}{|c||}{ Curso } \\
\cline { 3 - 4 } & & Licenciatura & Especialização Form. Prof. \\
\hline \multirow{4}{*}{ U2 } & 1 & Artes plásticas (C1) & Mídias na educação (C7) \\
\cline { 2 - 4 } & 2 & Agronomia (C2) & Prod. material didático para EaD (C8) \\
\cline { 2 - 4 } & 3 & Educ. física (C3) & Gestão escolar (C9) \\
\cline { 2 - 4 } & & Letras LIBRAS (C4) & \\
\cline { 2 - 4 } & & Biologia (C5) & \\
\cline { 2 - 4 } & & Ciências Agrárias & \\
& & & \\
\hline
\end{tabular}

A Tabela 1 ilustra a discrepância das informações entre cursos de licenciatura e especialização de uma universidade situada na região Norte do país. Os cursos $\mathrm{C} 1, \mathrm{C} 2$, C3 e C7 aparecem listados para esta instituição na CAPES/UAB; destes, apenas C1 e C3 estão em ambos os portais; C4, C5, C6, C8 e C9 aparecem apenas na IPES/EaD. Neste caso, percebe-se que a U2 apresenta: quatro cursos na base de dados da CAPES e sete no site da instituição. Além disso, cinco dos cursos da instituição não estão contemplados na CAPES/UAB e dois cursos (C2 e C7) estão na CAPES/UAB, mas não estão presentes na IPES. Aplicando este mesmo procedimento a todas as IPES que oferecem cursos de formação de professores via $\mathrm{EaD}$, ao final, a análise comparativa 


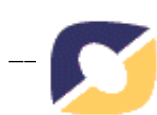

mostrou que, em relação ao número de cursos das instituições, existiam na CAPES/UAB 105 cursos a mais do que os registrados nos sites das IPES.

Deste modo, concluiu-se que o primeiro campo de pesquisa, o site da CAPES/UAB, apresentava informações desatualizadas, o que é evidenciado também pelo fato do site não especificar a data de atualização dos dados fornecidos. Cabe indicar que a opção pela CAPES/UAB como ponto de partida para o mapeamento dos dados para a pesquisa deve-se à responsabilidade desta instituição com a formação de professores para a educação básica a partir de programas da $\mathrm{UAB}^{5}$. Assim, em tese, este seria o local propicio para encontrar os dados atualizados. Para Gatti (2009, p.103), esta dificuldade já era esperada, uma vez que "a sistemática de coleta de dados dessa modalidade ainda não está inteiramente consolidada" em virtude do recente crescimento de cursos de graduação a distância.

Diante deste contexto de inexatidão de dados, decidiu-se lançar mão apenas dos portais das IPES, por julgar que estes têm mais condições de controlar suas informações do que a CAPES, a qual é responsável pela totalidade das instituições em âmbito nacional. Este novo mapeamento revelou que as regiões Nordeste e Sudeste possuem o maior número de universidades públicas (24) que oferecem cursos de formação docente na modalidade $\mathrm{EaD}$, seguidas pelo Sul com 12, Norte com oito e, por último, a região Centro-oeste com sete.

Com relação aos cursos de licenciatura, a Tabela 2 demonstra que a maior parte deles (129) está concentrada nas universidades federais, enquanto as estaduais são responsáveis por 59 cursos. A oferta de licenciaturas na região Nordeste se sobressai tanto em universidades estaduais (22 cursos) como nas federais (40 cursos), seguida pelas regiões Sul com 41 cursos, o Sudeste com 38, o Centro-oeste com 31 e por fim o Norte com 16.

Tabela 2: Mapeamento/distorção dos dados na CAPES/UAB e IPES/EaD.

\begin{tabular}{||c|c|c|c|c|c|c|c|c||}
\hline \multirow{3}{*}{ Região } & \multicolumn{7}{|c|}{ Instância / tipo de curso / fontes } \\
\cline { 2 - 10 } & \multicolumn{6}{|c|}{ Estadual } & \multicolumn{4}{c|}{ Federal } \\
\cline { 2 - 9 } & Licenciatura & \multicolumn{2}{|c|}{ Especialização } & \multicolumn{2}{c|}{ Licenciatura } & \multicolumn{2}{c|}{ Especialização } \\
\cline { 2 - 9 } & CAPES & Site IES & CAPES & Site IES & CAPES & Site IES & CAPES & Site IES \\
\hline Sul & 16 & 16 & 09 & 06 & 22 & 25 & 25 & 24 \\
\hline Norte & 05 & 04 & 00 & 00 & 15 & 12 & 04 & 04 \\
\hline Centro-oeste & 13 & 08 & 05 & 00 & $23^{*}$ & $23^{*}$ & 10 & 08 \\
\hline Sudeste & 13 & 09 & 04 & 01 & 43 & 29 & 40 & 17 \\
\hline Nordeste & 67 & 22 & 06 & 03 & 76 & 40 & 22 & 07 \\
\hline $\begin{array}{c}\text { Total por tipo } \\
\text { de curso e } \\
\text { fonte }\end{array}$ & 114 & 59 & 24 & 10 & 179 & 129 & 101 & 60 \\
\hline
\end{tabular}

Observação: ${ }^{*}$ ) Embora seja o mesmo número, os dados não se referem aos mesmos cursos.

No que se refere às especializações tem-se: 60 cursos na instância federal e dez na estadual, repetindo os índices da licenciatura. Em relação a este tipo de curso, o Sul é a região com maior número, com um total de 30 cursos, seguida da região Sudeste (18), o Nordeste com dez e Centro-oeste e Norte, respectivamente, com oito e quatro cursos de especialização.

Outro dado interessante se dá em relação ao número de cursos por região: somadas licenciaturas e especializações o maior oferecimento está no Nordeste, com 72 cursos. O Sul conta com apenas um curso a menos. Na sequência, se apresentam a região Sudeste com 56, o Centro-oeste com 39 e o Norte com 20. 


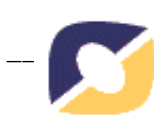

A licenciatura em Pedagogia é a mais ofertada, com 35 cursos no país. Destes, o primeiro lugar é da região Sul (nove) seguido do Sudeste e Nordeste com oito cursos cada. No Centro-oeste são sete cursos de Pedagogia e no Norte existem apenas três. No entanto, considerando Pedagogia como área pode-se incluir nesta contagem os cursos que aparecem como 'Educação do campo' (três cursos), 'Educação especial' (um), 'Pedagogia séries iniciais' (um) e 'Pedagogia para educação infantil' (dois) e isso fará crescer a oferta para 42 cursos no país. Isso vem ao encontro do que preconiza o relatório do CNE (2007, p.21) a respeito da "formação de professores por licenciaturas "polivalentes"”, como uma proposta de solução estrutural para a educação brasileira.

Tabela 3: Mapeamento dos seis primeiros cursos em número de oferta no país

\begin{tabular}{||c|c|c|c|c|c|c||}
\hline \hline Curso Região & Sul & Norte & $\begin{array}{c}\text { Centro- } \\
\text { oeste }\end{array}$ & Sudeste & Nordeste & $\begin{array}{c}\text { Total } \\
\text { (curso) }\end{array}$ \\
\hline *Pedagogia & 09 & 03 & 07 & 08 & 08 & 35 \\
\hline Matemática & 03 & 05 & 02 & 07 & 10 & 27 \\
\hline *Biologia & 05 & 05 & 08 & 01 & 08 & 27 \\
\hline Física & 04 & 02 & 02 & 03 & 05 & 16 \\
\hline *Letras Português & 04 & 03 & -- & 01 & 06 & 14 \\
\hline Química & -- & 02 & -- & 03 & 06 & 11 \\
\hline Total (região) & 27 & 20 & 20 & 30 & 41 & 138 \\
\hline \hline
\end{tabular}

Observação: (*) Constatando que existem nomes variados para cursos afins, surge a possibilidade de considerar os cursos indicados com * como áreas, aspecto que altera os índices totais por curso.

As licenciaturas em Matemática e Biologia ocupam o segundo lugar no ranking das graduações de formação de professores através da EaD. Para Matemática são contabilizados 27 cursos em todo o país, sendo que estão em maior número no Nordeste (10). O Sudeste conta com sete cursos e as regiões Norte, Sul e Centro-oeste ocupam respectivamente as demais colocações. Já no número total de cursos de Biologia, estão incluídos 14 cursos de Ciências Biológicas e dois de Ciências Naturais/Ciências. Deste modo, esta licenciatura ocuparia a terceira colocação em número de cursos se não fosse considerada como área.

A licenciatura em Física aparece em terceiro lugar com destaque para o Nordeste com cinco cursos. Logo aparecem: Sul com quatro, Sudeste com três e Norte e Centro-oeste com dois cursos cada. Na quarta colocação está Letras Português. No entanto, deve-se destacar que assim como aconteceu no caso da Biologia, sob a nomenclatura Letras Português estão dois cursos classificados apenas como Letras. O Nordeste registra a maior oferta deste curso (seis), seguido pela região Sul, Norte e Sudeste, com quatro, três e um curso respectivamente. O Centro-oeste não oferta este curso. Em quinto lugar na oferta de curso está a Química e novamente o Nordeste desponta com seis cursos, depois o Sudeste com três e por último o Norte com dois. As regiões Sul e Centro-oeste não registram o oferecimento de licenciatura em Química.

Esses dados são similares aos encontrados no Censo da Educação Superior de 2009. Ao se analisar os dados sobre os dez maiores cursos de graduação em número de matrículas ofertados na modalidade $\mathrm{EaD}$ percebe-se que, Pedagogia é o curso com mais oferta de vagas. Em seguida, selecionando apenas os que se referem à formação de professores, Letras aparece em segundo lugar, seguido de Matemática, Ciências Biológicas e História. Assim, embora haja consenso em relação à Pedagogia, existe uma 
disparidade nas demais colocações com relação a cursos ofertados e número de matrículas.

Esse mapeamento é relevante, sobretudo, se confrontado com os dados sobre formação específica por disciplina dos professores do Ensino Médio. O relatório do Conselho Nacional de Educação (CNE) sobre o déficit docente, publicado em 2007, registrou que entre as ciências exatas, apenas a Biologia conta com $56 \%$ dos professores com formação específica, em sala de aula. No entanto, Matemática, Química e Física são áreas com um contexto negativamente diferenciado, onde, respectivamente, apenas $27 \%, 13 \%$ e $9 \%$ de seus professores são formados na disciplina a qual lecionam. Iria Brzezinski (2011), presidente da Associação Nacional pela Formação dos Profissionais da Educação (ANFOPE) chama a atenção para estes mesmos dados a partir do Censo da Educação Básica de 2009. Ainda que tenham decorridos dois anos, os números continuam praticamente inalterados: Biologia aumentou três pontos percentuais, mas os demais cursos não obtiveram nenhuma melhora.

Os dados do Censo de 2009 indicam que a prioridade seria formar professores de Física, Química e Matemática, respectivamente. Estudos do Instituto Nacional de Estudos e Pesquisas Educacionais Anísio Teixeira (INEP) também demonstram que são necessários em torno de 60 mil professores, porém durante toda a década de 90 se formaram apenas 7.216 professores de Física e que algo parecido aconteceu na Química também (CNE, 2007 p. 11).

No entanto, ainda que o documento do CNE apresente "recomendações de curto e médio prazo que ajudem a minimizar o risco do apagão [do ensino médio]" (2007, p.17-18), parece que na realidade de hoje as medidas emergenciais, entre elas a própria UAB, ainda estão na contramão da realidade desvendada a partir das informações divulgadas. E isso se dá por dois motivos. O primeiro, pelo fato de que as licenciaturas em Física e Química registravam, no ano de 2007, por volta de $90 \%$ de professores atuando na disciplina sem a formação específica, e hoje Física é apenas o quarto curso em número de oferta no país e Química o quinto e ambas as licenciaturas parecem não ser foco das instituições e da UAB, tendo em vista os dados das matrículas. Somado a isso, aparece o segundo motivo: considerando que em 2004 os dados do Censo ${ }^{6}$ indicavam que na região Norte se localizavam as situações mais críticas no que se refere à formação docente, com $51 \%$ dos seus professores sem a licenciatura, verifica-se que esta condição reproduz-se novamente, uma vez que a região, a qual deveria ter a maior oferta de cursos, permanece com um oferecimento de vagas ainda discreto em todas as áreas.

\section{Considerações Finais}

As políticas públicas para formação de professores, instituídas a partir de 2004 trazem a educação a distância como a modalidade de educação considerada adequada para atender a histórica defasagem de formação de professores no Brasil. Esta política é materializada pelo programa Universidade Aberta do Brasil e recai sobre as universidades públicas a responsabilidade de formar os professores para melhoria da educação básica.

Neste estudo procurou-se conhecer o alcance das ações da UAB, ficando evidente que a maioria das universidades públicas aderiu à política governamental. Os dados demonstram que as demandas prioritárias, tanto em termos regionais como na área de conhecimento, não tem se efetivado. Uma das grandes dificuldades enfrentadas 
é a falta da publicação dos dados pelos órgãos do Governo, gerando distorções nas informações.

Portanto, os dados mostram que as universidades têm ofertado um número significativo de cursos de licenciatura em todo o Brasil. No entanto, percebe-se através do mapeamento inicial, que esse número expressivo na oferta não garante as atualizações dos dados do portal da CAPES/UAB que apresenta ausência e, por muitas vezes, discrepâncias dos dados disponibilizados, de modo que as informações que constam no portal não aparecem no site das IPES, tornando o campo da pesquisa limitado, além de dificultar estudos que ajudem a compreender o universo em que estão se efetivando estas políticas do Governo Federal.

A oferta de cursos de licenciatura está concentrada nas universidades federais, enquanto as estaduais são responsáveis por uma parcela menor. No que se refere ao número de universidades e número de cursos por região, dos cinco cursos analisados, o Nordeste se sobressai tanto em universidades estaduais como nas federais, seguida pelas regiões Sul, Sudeste, Centro-oeste e Norte. A licenciatura em Pedagogia é a mais ofertada, seguida das licenciaturas em Matemática e Biologia. A licenciatura em Física aparece em terceiro lugar e na quarta colocação temos Letras Português. Em quinto lugar na oferta de curso está Química.

Contudo, os dados demonstram que a oferta expressiva de cursos de licenciatura nas diferentes regiões do país, ainda não corresponde às reais necessidades de formação de professores apontadas como prioritárias pelas estatísticas oficiais.

\section{Notas do texto}

1 A criação de consórcios regionais é uma proposta mais ampla da Universidade Virtual Pública do Brasil (UNIREDE), um consórcio com instituições públicas de ensino superior tendo como objetivo democratizar o acesso à educação de qualidade por meio da oferta de cursos a distância, recebendo o apoio dos ministérios da Educação (MEC), da Ciência e Tecnologia (MCT) e de outros parceiros.

${ }^{2}$ http $/ /$ www.uab.capes.gov.br/index.php

3 Mapeamento realizado no período entre Fevereiro e Setembro de 2010. É interessante notar que outros estudos também se preocuparam em definir o número de instituições vinculadas à UAB e tomaram o mesmo portal como base de dados. Dourado (2008), por exemplo, identificou, em agosto de 2008, 49 instituições entre instituições federais e CEFETs; e Gatti (2009), em busca realizada em abril de 2009, encontrou 74 instituições, mas não especificou a que níveis de ensino ou a que categorias federativas estas instituições se referem.

${ }^{4}$ Foram criados códigos para não identificar explicitamente as instituições pesquisadas.

5 A CAPES teve suas ações ampliadas à formação de professores da educação básica a partir da Lei 11.502/2007.

${ }^{6}$ Censo Escolar 2004, INEP/SEED.

\section{Referências}

ALONSO, K. M. A expansão do ensino superior no Brasil e a EaD: dinâmicas e lugares. Educ. Soc. [online]. 2010, vol.31, n.113, pp. 1319-1335.

ALMEIDA, M. E. B. de. Transformações no trabalho e na formação docente na educação a distância on-line .Em Aberto, Brasîlia, v. 23, n. 84, p. 67-77, nov, 2010. 
BARRETO, R.G. Discursos, tecnologias, educação. Rio de Janeiro: EDUERJ, 2009. BELONI. M. L. O que é mídia-educação. Campinas (SP): Autores Associados; 1999.

. Ensaio sobre a educação a distância no Brasil. Educ. Soc., Abr 2002, vol.23, no.78, p.117-142. Disponível em < http://www.scielo.br/pdf/es/v23n78/a08v2378.pdf >. Acesso em: 15 mar. 2011.

BRASIL. Instituto Nacional de Estudos e Pesquisas Educacionais Anísio Teixeira/INEP. Sinopse Estatística do Ensino Superior. 2009. Disponível em: <http:/portal.inep.go v.br/superior-censosuperior-sinopse>. Acesso em: 05 mai. 2011.

Instituto Nacional de Estudos e Pesquisas Educacionais Anísio Teixeira/INEP. Resumo técnico. Censo da Educação Superior 2009. Brasilia, 2010. Disponível em: $\quad<\mathrm{http} / /$ portal.inep.gov.br/superior-censosuperior-relatorio_tecnico>. Acesso em: 05 mai. 2011.

- Instituto Nacional de Estudos e Pesquisas Educacionais Anísio Teixeira/INEP. Sinopse Estatística do Professor 2009. Disponível em: 〈http//portal.inep.gov.br/basica-censo-escolar-sinopse-sinopse>. Acesso em: 05 mai. 2011.

Ministério da Educação, Conselho Nacional de Educação. Ruiz, A. I.; Ramos, M. N.: Hingel, M. Escassez de professores no ensino médio: propostas estruturais e emergenciais. Mai, $2007 . \quad$ Disponível em: 〈http//portal.mec.gov.br/cne/arquivos/pdf/escassezl.pdf>. Acesso em: 18 mai. 2011.

Decreto $\mathrm{n}^{\circ}$ 5.800, de 8 de junho de 2006. Dispõe sobre o Sistema Universidade Aberta do Brasil - UAB. Decretos. Brasilia: Casa Civil da Presidência da República Federativa do Brasil/Subsecretaria para Assuntos Jurídicos, 2006. Disponível em: < http://www.uab.capes.gov.br/images/stories/downloads/legislacao/decreto5800.pdf $>$.

Acesso em: 06 mai. 2011.

BRZEZINSKI, I. Panorama das políticas de formação de professores da educação básica. Palestra. UFSC/CED. 03 mai 2011.

CERNY, Roseli Zen. Gestão pedagógica na educação a distância: análise de uma experiência na perspectiva da gestora. Tese de doutorado apresentada ao Setor de PósGraduação da Pontifícia Universidade Católica de São Paulo - PUC/SP. São Paulo, 2009.

CERNY, Roseli Zen; KONS, Sabrina Botelho; Teixeira, Graziela Gomes Stein. Do professor individual ao professor coletivo na EaD:da teoria à prática. I Encontro Internacional Tic e Educação; Lisboa-Portugal. 2010.

GATTI, B. A. (coord.); BARRETO, E. S. S. Professores do Brasil: impasses e desafios. Brasilia: Unesco, 2009.

GIDDENS, Anthony. As conseqüências da modernidade. Tradução de Raul Fiker. São Paulo: Universidade Estadual Paulista, 1991.

MARTINS, O. B. Os caminhos da EaD no Brasil. Rev. Diálogo Educ., Curitiba, v. 8, n. 24, p. 357-371, maio/ago. 2008. Disponível em: $<$ http $/ /$ www2.pucpr.br/reol/index.php/DIALOGO?dd1=2012\&dd99=view $>. \quad$ Acesso em: 06 mai. 2011.

MAYOR, F. O ensino superior e as novas tecnologias. Correio da UNESCO, Brasil, fev.1997. 